\title{
I am fast but I do not fit: an autoethnography of a swimmer's experiences of 'competitive performance' stigma in two sporting contexts
}

\author{
Jenny McMahon ${ }^{\mathrm{a}}$, Kerry R. McGannon ${ }^{\mathrm{b}}$ and Chris Zehntner ${ }^{\mathrm{a}}$

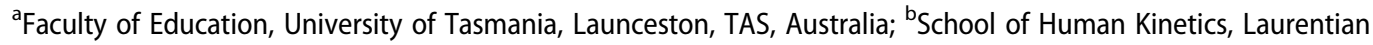 \\ University, Sudbury, ON, Canada
}

\begin{abstract}
Given that research outside of sport and exercise has found that stigma may cause severe consequences (e.g. depression), it is important to explore the concept in regard to its connection to socio-cultural issues in the development and persistence of stigmatisation in sporting contexts. Analytic autoethnography and Goffman's theory of stigma was used to explore one female swimmer's experiences of 'enacted' and 'felt' competitive performance stigma occurring in elite swimming and a masters swimming context. Competitive performance stigma has not been conceptualised or explored as a stigma type in sport research, however through the presentation and analysis of two vignettes and the use of Goffman, this is achieved. The social agents that contributed to both 'enacted' and 'felt' competitive performance stigma and the consequences/effects (e.g. withdrawal from sport, feelings of shame) for this swimmer are highlighted. Our analysis further highlights the role of particular cultural insiders (e.g. coaches, team managers and other swimmers) in the reproduction of competitive performance stigma through acts of labelling, discrimination and social isolation. These acts positioned the female swimmer as an 'outsider' because of her competitive performance which in turn led to her withdrawal from these two sporting contexts highlighting the implications for recipients of stigmatisation.
\end{abstract}

\section{ARTICLE HISTORY}

Received 14 March 2017

Accepted 27 June 2017

\section{KEYWORDS}

Masters sport; elite sport; coaching practice; creative analytical practices; goffman; athlete wellbeing

\section{Introduction}

Stigmatisation occurs when a person/athlete is perceived to deviate or differ from normative expectations and is subsequently 'typecasted', 'labelled', 'stereotyped', 'separated,' 'ostracised,' 'marginalised' or 'discriminated' against (Goffman, 1973; Link \& Phelan, 2001). Stigmatisation often involves pervasive negative representations of people who have (or are thought to have) a stigmatised characteristic, a feature that deviates from what is considered normal (Goffman, 1963). In this respect, stigma is socially constructed, influenced by culture and reflects the marking of difference among groups of people (Goffman, 1963), a marking that links to broader macro inequalities (Campbell \& Deacon, 2006), reproduced through language or actions. The concept of stigma is therefore complex because it is both a cause and a consequence of inequality or discrimination. Thus, power differentials play an integral part in the production of stigma (Parker \& Aggleton, 2003).

A number of scholars have investigated various types of stigmas occurring in sport and exercise contexts. For example, 'lesbian' athlete stigma was explored by Krane (1997, 2001); Kauer and Krane 
(2006) and Satore and Cunningham. Lesbian physical education teachers' experiences was studied by Edwards, Brown, and Smith (2016). Anderson (2002) investigated 'gay' athlete stigma. The stigmatisation of 'fat women' in fitness gyms was researched by Mansfield (2010). Cunningham (2008), Schmalz and Kerstetter (2006) examined 'gender' stigma in sporting contexts. Young, White, and McTeer (1994) explored the stigmatisation of the 'injured athlete' while athletes stigmatised as a result of 'mental illness' was investigated by Gulliver, Griffiths, and Christensen (2010).

The consequences of stigma are varied, however in all cases, have serious implications/consequences for the stigmatised recipient/s such as lower salaries, exclusion and discrimination (Krane, 1997, 2001); self-withdrawal from the sporting context (Schmalz \& Kerstetter, 2006); concealment of sexual identity (Edwards et al., 2016) as well as anxiety, shame and embarrassment (Mansfield, 2010). In the research conducted by Kauer and Krane (2006), it was revealed that female college athletes felt pressured to accept the sexual advances of men for fear of being labelled 'lesbian' highlighting their fear of being stigmatised, subverting their identities.

While Goffman (1973) did not discuss 'competitive performance' stigma specifically in his work on the 'spoiled identity', he did shed light on those people who are unable to fulfil normal physical activities due to an incapacity (i.e. amputees) and are subsequently 'type-casted' and viewed as abnormal, physically incompetent or inferior human beings. In the sporting context specifically, Taub, Blinde, and Greer (1999) found many athletes with physical impairments were often 'stigmatised because their bodies are assumed to vary from norms of physical competence and bodily appearance' (p. 1469). Goffman's (1973) and Taub et al. (1999) conceptions of 'physical incapacity' and 'physical incompetence' are important in terms of this present paper, as a means of assisting us to make sense of athletes who have come to be stigmatised because they are unable to display the physical requirements necessary for competitive performance (i.e. winning) and thus meet the meritocratic ${ }^{1}$ expectations of that culture. As such, athletes who are seen to be physically incompetent and unable to meet competitive performance expectations may become 'typecasted', 'labelled', 'stereotyped', 'separated,' 'ostracised,' 'marginalised' or 'discriminated against' (see Goffman, 1973; Link \& Phelan, 2001). Although sport and exercise research has not explicitly utilised the work of Goffman as articulated here in in terms of competitive performance, the emphasis on performance and a similar example of the foregoing ideas can be found in physical education research conducted by Evans, Rich, and Holroyd (2004). In their work, Evans et al. (2004) found performance codes to be operating in discourses of competition and achievement (i.e. physical education contexts; sporting contexts) (Evans \& Davies, 2004). Performance codes relates to practices, pedagogies and social interactions that are implemented in the name of achieving a physically performing body. Evans et al.'s (2004) notion of performance codes was used by McMahon (2010) to investigate elite swimming culture, in order to hone into the social practices and pedagogy that focused on the output of the competitive performance of swimmers. It was found in this research that elite swimmers were viewed as malleable objects (McMahon, Penney, \& Dinan-Thompson, 2012), trained and manipulated to a perceived ideal for the sake of competitive performance. While this aforementioned work on performance codes primarily focuses on practices and social interactions that aim to enhance the body's utility, productivity and performance through regulation, this present study focuses on the mechanisms of constraint for an athlete who does not meet the performance code (Evans et al., 2004).

Like other forms of stigma that have been found to occur in the sporting contexts outlined above, competitive performance stigma could be seen to operate as a powerful mechanism of social control with serious consequences for the recipient (e.g. discrimination, psychological distress, identity subversion, withdrawal from physical activity). It must also be ascertained that 'competitive performance' is indeed relative to specific sporting contexts, constructed by the members' expectations in that context. For example, competitive performance expectations in elite swimming culture (i.e. winning a medal at the World Championships or Olympics) (McMahon 2010) would differ to the Masters level context.

There are a number of reasons why investigating stigma occurring in sport and exercise contexts is advantageous. First, as Goffman $(1973,1981)$ explains, every interaction, no matter how apparently 
minor it may seem, is consequential with the socially stigmatised being a major area of concern which warrants further investigation. This is because understanding more about stigma makes known disproportionate power, social control and the cultural treatment of members who deviate from normative and cultural expectations (Goffman, 1973, 1981; Link \& Phelan, 2001). To date, no researchers have explored stigmatisation occurring as a result of 'competitive performance' as articulated in this manner, which we argue in the present paper as being experienced by one swimmer in the masters and elite swimming contexts in Australia. Defining competitive performance as a stigma is useful for a number of reasons. First, as Goffman $(1973,1981)$ as well as Link and Phelan (2001) state, it is important to understand more about the cultural treatment of members who deviate from cultural expectations (i.e. competitive performance) with the hope that interventions or strategies may be formulated and implemented to mitigate it. As Link and Phelan (2001) explain, when prejudice and discrimination remains, there is an inherent need to understand more by focusing on the relationships between the stigmatised individual/s and those agents of social control defining the stigma. In so doing, through the analysis of stigma in the masters swimming and elite swimming context, the findings can be used to understand more about what is occurring for athletes in these two contexts, particularly those who fail to meeting cultural 'ideals'.

As previous research investigating stigma has lacked lived experience (Wigginton \& Setchell, 2016; Kleinman et al., 1995), this present study offers a unique perspective in relation to competitive performance stigma, what it can mean and how it was experienced by a swimmer who was immersed in both an elite swimming context and a masters swimming context. This is important in terms of contributing an understanding of stigma in these two specific contexts, and how it may come to affect an athlete. As stigma is socially constructed, it varies from context to context, therefore an insider perspective is essential. In so doing, through the use of McMahon's vignettes detailing her lived experiences, competitive performance stigma will be explored from a first-hand perspective. While more will be said about autoethnography shortly, it was noted by Kleinman et al. (1995) that many social scientists investigating stigma have faced challenges because they have studied stigma from the vantage point of theories that are uninformed by lived experience of the stigmatised recipient (Kleinman et al., 1995). Shneider (1988) provides an example of this explaining that writing about the experience of disability as an able-bodied researcher give priority to scientific theories and research techniques rather than to the words and perceptions of stigmatised. The result may be misunderstandings of the experiences of the people who are stigmatised and the perpetuation of unsubstantiated assumptions (Kleinman et al., 1995; Schneider, 1988; Wigginton \& Setchell, 2016). One way of overcoming this shortfall is explained by Wigginton and Setchell (2016) who highlights the need for 'insider' research as research conducted by cultural outsiders may be misdirected due to a lack of nuanced knowledge about the specific context/culture. Thus, the use of McMahon's 'insider' perspective can potentially highlight issues of power and privilege occurring in the two contexts of elite swimming and masters swimming in Australia, which in turn may have direct implications for the stigmatised (Link \& Phelan, 2001; Wigginton \& Setchell, 2016). One such implication is that stigmatisation may operate to reinforce, and perhaps even accentuate, the differential statuses and group memberships in sport and sport organisations (Satore \& Cunningham, 2009). Another implication is that social stereotypes in sporting contexts affect short term and long term participation in sport and physical activity (see Schmalz \& Kerstetter, 2006). While there is variation across specific contexts in what characteristics are stigmatised, what remains consistent are the social and psychological consequences that occur which have come to include avoidance, rejection, devalued or deviant identity, social isolation, depression and marginalisation (Goffman, 1973; Link \& Phelan, 2001) thus highlighting the importance of this research investigation.

Outside of sport and exercise literature, a number of different studies (i.e. Scambler, 2004) have used the concept of stigma in a wider sense, specifically to understand more about it. Scambler (2004), in his work on epilepsy, used the terms 'felt' stigma and 'enacted' stigma to identify how 
stigmatisation occurs (i.e. enacted) and what results for the recipient of the stigma (i.e. felt). Specifically, 'enacted stigma' can be described as instances of overt rejection or discrimination experienced by the stigmatised individual due to a key distinction or characteristic (Gray, 2002). While 'felt stigma', also known as 'self-stigma', refers to feelings of shame for possessing an attribute that is not seen as normal for fear of facing enacted stigma (Lekas, Siegel, \& Leider, 2011). The distinction between 'enacted' and 'felt' stigma is important to recognise because 'enacted' stigma indicates that the interactional context has broken down and that the individual is being discriminated (Scambler, 2004). 'Felt' stigma is also significant because it refers to an individual's fear of failing to enact a normal disposition. In so doing, stigmatisation affects not only how individuals perceive themselves (i.e. felt stigma), but also how others treat them if a point of difference is discovered (i.e. enacted stigma) (Crocker, Major, \& Steele, 1998).

\section{Purpose and research questions}

Two overarching research questions will be used to explore 'enacted' and 'felt' stigma through the two vignettes. These two questions were adapted from Gray's (2002) research which studied 'enacted' and 'felt' stigma for parents of children with high functioning autism as well as Scambler's (2004) previous research. Specifically, the first research question will be used to explore 'enacted' stigma (i.e. instances of overt rejection or discrimination).

(1) According to one female swimmer, how was she treated differently because of her competitive performance in elite Australian swimming culture and Masters swimming culture?

The second research question will be used to explore 'felt' stigma (i.e. feelings of shame because of a characteristic of difference).

(2) How did the swimmer feel about herself as a result of being treated differently for her competitive performance in these two sporting contexts?

While this research centres on one female athlete's experiences in the elite and masters context, it provides the opportunity to shed light on other athletes' experiences who may be in a similar circumstance, however 'may have been silenced, devalued or underrepresented' (Douglas, 2009, p. 188). Allen-Collinson and Hockey (2008) further explain how providing insight into one athlete's experiences is important as it potentially provides the opportunity to illuminate wider cultural and subcultural issues. These points above made by Douglas (2009) as well as Allen-Collinson and Hockey (2008) have also been noted in the work of Smith (2017), Sparkes (2004) and Ellis and Bochner (2000) who highlight how individual stories or accounts provide the opportunity for lived experience to be connected to the surrounding socio-cultural structures.

In relation to stigma specifically, Wahab (2003) explains that it is important to empower the voice of the stigmatised which is being done in this research, because they are the ones who experience oppression, stigmatisation and alienation and are therefore viewed as experts in their own subjugated social standings. In so doing, this can provide alternative views of reality that may lead to social change (Wahab, 2003). Therefore through the telling of one female athlete's experiences of competitive performance stigma, the audience (i.e. academics, other athletes, sport practitioners) are invited to come into her world as a swimmer, having the opportunity to view and engage with alternate ways of knowing. Indeed, this female swimmer offers a unique perspective of these two sporting contexts (i.e. elite and masters swimming), providing a firsthand athlete account of both of these contexts. This is something that cannot be replicated from the sidelines, from a coach or parent perspective (McMahon, Zehntner, \& McGannon, 2017) or from an armchair expert (Smith, 2016). This firsthand perspective in turn can potentially initiate change (McMahon, McGannon, \& Zehntner, 2017). 


\section{Methodology: analytic autoethnography}

When considering the appropriate methodology for this investigation, a number of factors were considered. First, it was of utmost importance to empower the voice of McMahon who doubles as the research participant and lead researcher in this investigation. We also wanted to provide her with the opportunity to bring to the fore her inner most feelings, emotions as well as her lived experiences in sport. As Douglas (2009) explains, it is important for researchers to make known what athletes' sporting experiences are like by making use of their own voices and perspectives. For example, as an elite golf player, Douglas (2009) highlighted how scientific research had consistently failed to represent her experiences in sport. Therefore, Douglas (2009) highlighted the inherent need for athletes to empower their own voice and experiences in research to legitimise their ways of being in sport.

Another consideration when seeking the appropriate methodology was that we did not want to misrepresent McMahon's lived experience as flagged by Kleinman et al. (1995) as a weakness in previous stigma research. Instead we wanted to enable her with the opportunity to tell her lived experiences from the perspective of a cultural insider, in ways that she felt best represented the actual experience and the personal and social meanings of them (Parry \& Johnson, 2007). Third, reaching the audience (reader) was also important. Thus, we wanted to employ an approach that would appeal to the audience in ways that were familiar to them with the hope of impacting them. Through the use of an approach that may appeal to the audience, they may indeed be able to resonate, particularly those who may have been recipients of stigmatisation. Owton and Sparkes (2015) also makes an important point saying that once the audience (readers) have engaged with others' lived experiences, they cannot claim that they have not heard it so it is important to present lived experiences in familiar ways (i.e. story-telling).

In view of these points, analytic autoethnography was chosen because it aligned with these considerations. The inclusion and emphasis of lived experience and personal stories made social constructionism an appropriate epistemological framework for this autoethnographic exploration.

\section{Analytic autoethnography: definitions and process}

More than a decade ago, Ellis and Bochner (2000) provided an umbrella definition of autoethnography noting that, 'autoethnography is an autobiographical genre of writing and research that displays multiple layers of consciousness, connecting the personal to the cultural' (p. 739). However, since then, autoethnography has come to include a number of other different strands (i.e. evocative; analytic; meta-autoethnography etc.). Within the present research, analytic autoethnography is where stories of experience are produced by one person and similar to other authoethnographic forms which aim to be evocative. However, when taking up analytic autoethnography, a theoretical autopsy (i.e. analysis) of the stories occurs (Anderson, 2006). In this respect, rather than operating as an artful writer-persuader, the autoethnographic researcher writes as a 'declarative author-persuader' (Barone, 2000), by seeking direct control over the interpretations placed on a story in the act of reading, listening, watching and so on (Smith, 2017). Analytic authoethnography was utilised in the case of McMahon's stories in order to make known the subtle and not so subtle acts of stigmatisation that may be occurring for one swimmer within two sporting contexts, potentially raising the audience's consciousness to practices that indeed may have become normalised and/or taken for granted. In this respect, the purpose of analytic autoethnography was not solely to document the personal experiences of McMahon, but provide the audience with the opportunity to 'gain insight into some broader set of social phenomena than those provided by the data themselves' (Anderson, 2006 , p. 387). Some examples of analytic autoethnography that shed light on sporting/physical culture can be found in Allen-Collinson's (2005) rare insight into her injured sporting body, Carless (2012) autoethnographic work on sexual orientation, sexual identity and masculinity in the context 
of school sport as well as McMahon and Dinan-Thompson's (2011) autoethnographic work on detrimental body practices occurring in elite Australian swimming culture.

\section{Method}

As McMahon was a former elite swimmer who represented Australian numerous times during her adolescence and for the last ten years participated in a masters swimming context, the two vignettes that follow centre on two specific encounters from these two sporting contexts. Further, as two different time frames outlining McMahon's lived experiences in two different sporting contexts (i.e. elite/ masters swimming) are outlined, two different methods were subsequently employed which included; emotional recall strategy and diary entries at the actual time the lived encounters occurred. Each of these will be discussed in turn.

\section{Transcribing the lived encounters}

When outlining her adolescent lived experience in elite Australian swimming culture, McMahon used two strategies. The first strategy was 'emotional recall' proposed by Ellis and Bochner (2000) whereby McMahon visualised her presence back in the scene physically and emotionally. During the re-calling of events, McMahon re-visited photographs and video footage taken during the time that she was that 16-year-old world-class swimmer, which better enabled her to visualise being back in that context so she could recall the sights and sounds that were present during that time. As noted by Ellis and Bochner (2000), this strategy is effective for the retelling of a self-story because, 'if you can revisit the scene emotionally, then you remember other details' (p. 752). The second strategy included the sharing of McMahon's written stories with swimmers from the same specific context that McMahon had transcribed in her stories. These swimmers were able to resonate and in some instances provided further details that McMahon had forgotten to include or omitted. In turn, this provided a far richer and detailed storied account/s.

The story that outlined McMahon's experiences in Masters swimming culture was initially transcribed into her personal diary on the day the actual incident occurred. The following day, McMahon typed the encounter in full, when she then shared it with another masters swimmer (not related to McMahon) who was present during the actual encounter documented. He was able to resonate and suggested including further details (i.e. making a point of how long it took influential club members to make decision) that McMahon had omitted due to word restrictions with paper submission. His voice is reflected on below.

\footnotetext{
I was at first surprised and then annoyed at how friends of mine handled the incident that night. When I read the story of how you had been singled out for what I saw as punishment for being good, it opened my eyes to how you are positioned as an "other." I got to see how it impacted you. I hadn't looked at it through your eyes and I should have. When I read the story from your point of view, I began to see additional layers of behaviour that were troubling from that night. For instance, in your story, I feel that you have to make a better point about how long the decision makers were huddled for at the end of the race. It was like they were trying to rework a "problem" and seemed very intent on looking for a way out. Another point that you left out was when you were told that you were not eligible or were going to be penalised, the decision makers were very dismissive and laughed off any need to further explain themselves to you. What I also found interesting and you cannot really include because you did not see it happen but other club-mates seemed to enjoy the decision. It was almost like they were baying in support of the decision. This occurred in the change room and what I refer to as banter. They said stuff like "she should just cop it on the chin, after all she did represent Australia"... As though this was in some way a prize won and in need of distribution.
}

\section{Formatting the stories}

A number of formatting considerations were included in order to or separate McMahon's autoethnographic/story-telling voice from the academic. Specifically, an adaption of Sparkes' (2004) personal 
and academic voice framework was applied, whereby the autoethnographic representations were italicised. For example, direct speech is delineated through the use of quotation marks as well as being indented. Inner feelings are indented but quotation marks not used (McMahon, 2010). Sometimes certain words were capitalised within the autoethnography to highlight a point and/or give emphasis to her feelings and emotional experiences during the writing (McMahon, 2010; McMahon et al., 2012).

\section{Autoethnographic analysis}

Aligning with the analytic autoethnographic approach, prominent threads, tensions and themes were highlighted by the research team in the two vignettes in relation to the two key research questions as these related specifically to 'enacted' and 'felt' stigma. This approach aligns with Braun and Clarke's (2006) assertion that a theme captures something important about the data in relation to the research question/s. Specifically, when identifying if 'enacted' stigma occurred, we looked for occurrences where McMahon was 'type casted', 'labelled', 'stereotyped', 'ostracised', 'marginalised' or 'discriminated' within the story, as a result of her competitive performance. When identifying whether 'felt' stigma occurred, we looked to see if McMahon displayed feelings of shame in relation to her competitive performance.

\section{Ethics}

Ethical considerations were an important aspect of this autoethnographic research. Therefore, a number of strategies were implemented to ensure ethical standards were adhered to. To this end, our first ethical consideration was aspiration ethics. Sparkes and Smith (2014) as well as Lahman, Geist, Rodriguez, Graglia, and DeRoche (2011) explain that aspirational ethics is when the researchers strive for ethics greater than the minimum standard. In this respect, we strove to make research decisions in a non-exploitative as we were consciously aware of our role as researchers (Ellis, 2007) in and through the research process. To ensure aspirational ethics was achieved, the below ethical points were implemented.

Our second ethical consideration was to protect those who feature, albeit indirectly in the autoethnographic stories. Sparkes (in press) explains how autoethnography is a research genre dependent on relationships, and other people are always woven into the stories we tell, some intricately and deeply so. In this respect, it was important for us as the researchers to protect those people who feature in the stories that are told. In order to achieve this, McMahon used pseudonyms when transcribing the stories and also omitted physical, psychological and contextual characteristics of the individuals referred to, or implied, so that their identities were protected.

Our third ethical consideration related to whether or not informed consent needed to be obtained from those people who indirectly feature within the stories. Most recently Bochner and Ellis (2016) discussed the notion of informed consent and the blurry waters surrounding this important ethical issue. If informed consent has not been gained and those characters included have not read the stories or if permission has not been sought to include them (as is the case in this research), it does not mean that researchers cannot publish the research (Bochner \& Ellis, 2016). What it does mean is that the utmost care and consideration should be undertaken by researchers using 'interpretive authority' in regard to the stories (Bochner \& Ellis, 2016, p. 148). In this respect, the researcher/s need to be accountable for what they do and do not include, and moreover, how they interpret the results (Bochner \& Ellis, 2016). For Lopate (2013), interpretive authority enabled him as the autoethnographer to decide what gets included in his story rather than giving another person the power to decide. He feels these 'decisions are his moral dilemma, his ethical burden, and he should not make them someone elses' (cited in Bochner \& Ellis, 2016, p. 148). As Bochner and Ellis (2016) summarise, we cannot always know or predict the effects of our words on another or the offence it may cause, 
but we should be mindful in our writing to minimise any possible hurt. Thus, McMahon was mindful in the writing of her experiences so any possible hurt was minimised. In so doing, she has not included any details that were told to her in confidence and taken utmost care to protect the identity of those included indirectly.

\section{The 'Ex Australian swimming representative': in masters swimming}

I arrive to the pool for my first swimming session in weeks. I have not long arrived before a Masters swimmer (club mate) approaches me.

Masters swimmer: "Hey *Justine, how fit are you at the moment?"

I am unsure as to how I should answer that sort of question? Does s/he mean 'fit' in terms of me being an Australian swimming representative or does s/he mean fit in terms of masters competition? I am nowhere near fit in terms of elite swimming nor am I anywhere near my peak fitness in masters competition. However, on any given day, I know I could still jump in the water and swim faster than most of the guys and girls I train with. However, given that I have not swum for the last five weeks, I respond cautiously.

Me: "Not fit!"

The masters swimmer does not engage me in any further conversation and walks off. I am left wondering why $s /$ he asked. I can only assume that $s /$ he is also unfit and perhaps wanted to jump in my lane so we could negotiate our first session back together. I then notice that the masters swimmer in question walks up to another person who has quite a bit of speed and I overhear them say the following.

Masters swimmer: "the club is holding a competition. The rules are that you have to team up with one other person of the opposite sex and you have to have a combined age of over 85 years. For each year that your team is over the combined age of 85 , you get a one second advantage (for example if you have a combined age of 90, you would get five seconds deducted from your overall time). It is a medley relay and you have to swim two legs each. Do you want to be in my team? It will be held in three weeks. There is a prize up for grabs for the winning team."

I notice the swimmer they are talking to nodding obligingly and then they start to giggle as they think of a team name for themselves.

I chuckle on the inside because I now realise why they were asking how fit I was. My competitive instinct also kicks in and I feel quietly confident as I know there is no other female swimmer that comes close to my speed in the form strokes (i.e. backstroke; breastroke). In the middle of training that evening, I ask the coach about the impending competition. He repeats the same details as what I overheard my club mate say earlier. The coach really encourages me to participate. During the session, the squad is buzzing with excitement. Everyone is securing their team mate and formulating the most hilarious team names. While this is all going down, nobody else in the club secures me as their team mate. So, my husband who is a former competitive swimmer and also a member of the masters club and I decide to team up together. Ironically, nobody asked him to be on their team either. We fit the over 85 years criteria. In fact, our combined age is 89 years so we will be eligible to get a four second time advantage according to the rules outlined by the coach. My husband and I decide that I will do the backstroke and breastroke and he will do butterfly and freestyle.

Competition day approaches quickly. Just before the race start, all the team names are recorded on the white board so the final times can be easily recorded. The coach also announces right before the race that we do not have to swim the medley in the conventional relay order (i.e. backstroke; breastroke; butterfly; freestyle). We can do it in whatever order we want. My husband and I decided that I will go first doing backstroke and he will go second doing butterfly. I will then go third doing breaststroke and he will swim fourth doing freestyle. My husband and I love competition and when it came time to race, we race hard. We recorded a time $14 \mathrm{~s}$ faster than any other team. Our time is recorded on the whiteboard which everyone can see. As the remainder of the teams complete their relay and get their times recorded, it becomes quickly apparent that nobody is going to come close to the time that my husband and l achieved. We are still the fastest by $14 \mathrm{~s}$. At the end of the competition, two influential members of the club (one of which also raced) spend the next 15 min closely examining the times on the white board and applying the time advantages. As I grab my towel, notice the two of them pointing at the board, scratching their heads and looking down towards where my husband 
and I are standing. My husband and I decide to head to the communal showers because they are taking so long. For us, it is clear cut as we were convincingly the fastest. While we are in the showers, one of the influential club members is about to leave but has time to yell that we came second. I ask who won?

They respond, "Bradley and Julie!"

Me: "How? We beat them by $14 \mathrm{~s}$ and they are only one year older than our combined age."

The influential club member then responds saying that I was penalised $15 \mathrm{~s}$ for being an ex-Australian swimming representative. I then ask why I was penalised $15 \mathrm{~s}$ only decided after we won by $14 \mathrm{~s}$

The influential club member does not respond, instead shrugging and walking off.

The other person who decided to penalise me then walks out to leave but before they do, they yell at me laughing.

"Don't get technical Justine."

Heaviness drapes over my shoulders. I suddenly feel overwhelmed by a flood of emotions and I wonder why they are penalising me $15 \mathrm{~s}$ when I represented Australia in swimming nearly 27 years ago? A flood of thoughts and emotions overcome me and I try to rationalise them.

I thought I was accepted and one of them. I wonder what I have done wrong? I used to think that this was a space where I finally fit. A space where I was finally accepted for who I am. Why are they ostracising me for my performance? Maybe I should not have swam so fast. Why are they punishing me for how I swam? Maybe they don't like me being part of the club? I think they want me out of the club.

Then my thoughts shift to self-protection mode.

I have to isolate myself from them. Need to protect myself as I am not one of them and this is no longer my safe space.

\section{Postscript}

I am an educated informed and motivated researcher into the ways in which power and social agents can affect me. I know how systems and people can manipulate. Yet eight months has passed, and I find myself sitting at home isolated from everyone. I have purposely withdrawn myself from the masters group socially and physically as a method of self-protection. This group, I swum and socialised with. Now I avoid all activities with them. I also avoid the sport of swimming, a sport that has given me so much joy, a sport that I used as a way of metaphorically washing away my troubles and maintaining some semblance of who I am in this world. My wellbeing, both mental and physical is beginning to be affected by this incident. I find myself dwelling on the similarities between my elite swimmer experiences and what I thought would be a more safe and inclusive group (masters swimming). I wonder whether I will feel the same enjoyment that I got from swimming again without associating it with this encounter. To the casual observer, I am probably gifted with many great things in my life, but my swimming ability was not one of those things. I became a good swimmer through hours, months and years of sacrifice, pain and abuse.

Is my ability to swim fast now something that I should be ashamed of, and hide from others?

Is there even a space where I can take my physically tested and tortured body and feel included, safe or even proud of how it has carried me?

\section{The 'Has been' at 16: elite swimming culture}

My muscles are tingling with nerves. I am in the World Championships marshalling area. We are called by the marshaller to line up in preparation to walk out for the heat of the $4 \times 100$ freestyle relay. The four girls from Canada line up first as they are in lane 8, then the girls from Italy line up next, then 
Australia is in lane 6. As we all walk out of the marshalling area, the Perth crowd erupts. We stop behind our lane. I take off my tracksuit ready for my swim. I am the lead off swimmer in the relay. The whistle blows and I climb onto the starting blocks ready for the start. The crowd is silent.

Get it together Justine. Focus! 2 laps.

Bang, the gun goes off and I dive into the water. The lead out girls from the other countries are so quick, much quicker than I anticipated and are well ahead of me at the fifty-metre mark. I swim faster than I should in the third 25 metres, trying to make up lost ground which is not part of my race plan. I hang on in the last 25 metres as my body succumbs to the heaviness of lactic acid. I touch the wall in fifth. The second Australian girl dives in and swims her leg. As my third team mate dives in to swim her leg, I try to work out the split time of my team mate who swam second. I do the same with my team mate who is swimming third but get lost doing the calculations. All I know is that my lead out time was not that great. We qualify for the finals to be held that evening. At the end of the race, we all walk through the tunnel to the warm down pool. The coaches and team managers are waiting there. They rush up to the other girls in the team and point to the program that they are holding. I think they are sharing their splits with them. They are smiling so I assume they have done good splits. I know my split because I was the first swimmer but I wonder why the coaches and managers are avoiding talking to me. I dive into the warm down pool and do my usual post-race session to remove the lactic acid. When I finish, I grab my towel which is where my team-mates left their towels. They have already completed their warm down and are drying off. I ask them what splits they did. They each tell me their times and I realise that I was the slowest. The coaches and managers still avoid me and say nothing about my swim.

I feel like a failure because I know I have just failed to meet their expectations in the pool. I just want to hide. I don't feel worthy of being part of this Australian team.

That afternoon, we have our compulsory full team meeting before leaving for the finals.

I wonder if I am still in the relay team as no coach or team manager has told me otherwise. Not one coach or manager has said anything to me since before my race this morning.

One of the team managers starts the meeting and goes through his normal announcements such as who does not need to attend the finals session tonight because they are racing tomorrow. Then he announces who is swimming tonight in the finals as he always does each day. He announces how our $4 \times 100$ freestyle relay qualified fifth fastest tonight and are in the final. He then says that "Kat, Miranda, Tanya and Helen" will do us proud but he does not say my name.

Does that mean I am out of the relay team?

I feel like a failure. I am ashamed of my performance and I have obviously disappointed coaches and team managers as they are avoiding me. Before the team manager wraps up the meeting, he explains how some of us Australian team members have the opportunity to go to a local swimming meet and present medals at the end of the world championship competition. He asks for volunteers to let him know in the next day if they want to attend. He then wraps up the meeting.

Need to feel worthy of being part of the team again. Just want to be one of them.

I immediately go up to him and express my interest in presenting medals at the local meet. At least he cannot ignore me if I ask him a direct question. However, his response is not what I expected.

"Justine, I do not think they would want a has been presenting the medals."

He then walks off without so much of another word. I feel crushed. I want to go to my room and hide but I have to wish my team mates the best for the final of the relay tonight. I walk towards them and make eye contact as I approach them but they rush off as they see me approaching. 
Did they just rush off to avoid me? Or was it coincidental?

Now my team mates think I am not worthy of being part of this team. I just want to fit again like I did at Commonwealth Games. The silence is killing me. I feel so alone. I only have myself to blame for my performance and their silent treatment.

\section{Post script}

I visualise being on the medal dais. I am receiving my Commonwealth Games silver medal. The Australian flag is being raised.

I want that feeling again.

Outsiders may think that I want that feeling again because of the self-satisfaction and self-achievement of competitive performance but that is only a very small part of it. I want to achieve competitively again most of all because I want to feel accepted by the coaches, team managers and the other swimmers. The feeling of acceptance is something that fills a void in me, something I so desperately crave. I am willing to do anything to fix my body and my fitness so I can competitively achieve again and gain 'their' acceptance. The alarm sounds at 4.30am. I open the grey bottle of pills beside my bed. They are diet pills. I take three, one more than I should. I then open the yellow bottle of pills beside my bed. They are caffeine tablets. I take two. I arrive at the pool early. Am there for the next three hours and swim seven kilometres. As I am getting out of the pool, I say "time for the gym" just loud enough so my team mates and coach can hear. I want them to see me as committed. I get to the gym and I hop onto the exercise bike first.

Have to burn 1000 calories!

I ride the bike for an hour but the machine says I have only burned 350 calories. That is not enough as I have to burn at least 1000 calories. So, I get off the bike and get onto the treadmill. I start running and burn 650 calories during the next hour. When I get to the 12-kilometre mark, I decide it is not enough. I increase my goal.

Have to burn 1500 calories!

I run for another $45 \mathrm{~min}$. I look down at the monitor. Sweat is dripping off me. I have burnt 1500 calories and have run 20 kilometres. I am exhausted. Swim training this afternoon is going to hurt.

That evening at $8.15 \mathrm{pm}$, I reach into the cupboard and find two familiar feeling containers of tablets. I open the lids of them. One bottle has laxatives. I tip the bottle into my hand so I have seven tablets. Seven won't do it. I tip the bottle again until I have ten. I then open the lid of the other bottle. I tip three tablets into my palm. I cannot wait to feel my body succumb to them. They are valium. I take them to sleep because the diet pills and caffeine keep me awake. Will do anything, take anything that will help me to achieve competitively and so I can gain their acceptance. I don't care if it risks my health (McMahon, 2010; McMahon, McGannon, et al., 2017).

\section{Analysis/Closing}

This paper outlines one female swimmer's perceptions of competitive performance stigma in elite swimming and a masters swimming context in Australia. It is important to highlight that McMahon's stories are her perceptions of encounters that she endured and should be in no way thought of as representative of all. Indeed others (i.e. within each of these specific sporting contexts) may view her experiences differently.

Borrowing from Goffman (1973) and Link and Phelan (2001), the two autoethnographic accounts reveal how the swimmer was stigmatised as a result of her competitive performance as she deviated from the performance expectations of the two sporting cultures. This highlights Shilling's (1993) notion where the [swimmer] body is a source of physical capital, 'the possessor of power, status and symbolic forms' (p. 127). While previous research in the elite swimming context revealed how 
performing competitive swimmer bodies brought reward in the form of social privilege (McMahon, 2010), this research has highlighted how for one swimmer, when her body failed to perform competitively, she was stigmatised and subsequently 'labelled', 'discriminated' and 'socially ostracised' (Goffman, 1973; Link \& Phelan, 2001). In a contrast, in the masters swimming context, the swimmer revealed how she was discriminated for her extreme competitive performance through the implementation of an unnecessary penalty. Below, we expand on these points to address the two specific research questions specifically, those being how the swimmer participant (McMahon) experienced 'enacted' and 'felt' stigma.

\section{Enacted stigma}

Link and Phelan (2001) suggest that stigma can only be enacted where there is unbalanced power relationships-specifically, when the person with the stigmatised trait has less power than those who stigmatise him or her. Within each of the two stories, McMahon experienced being treated differently because of her competitive performance and was subjected to 'enacted' stigma. In both swimming contexts, at the time 'enacted' stigma occurred, she was an athlete, with stigma being enacted by a coach, team manager or club committee member, highlighting the disproportionate power relationships occurring in both of these contexts. This finding is no surprise given that previous research into Australian swimming culture has highlighted the disproportionate power relationships occurring between athlete and coaches as well as mentor and mentee coaches (Zehntner \& McMahon, 2014).

Enacted stigma was played out in similar, yet also different ways in both of these contexts. For instance, in the elite swimming context, discrimination was experienced by the swimmer due to her being positioned by others (e.g. coaches, team managers, other swimmers) as obtaining a subpar, lacking performance at the World Swimming championships. In turn, she was socially ostracised by coaches, team managers as well as her team-mates and given the silent treatment. The team manager's actions, when he labelled her 'a has been' preventing her from presenting medals at a local swimming meet further highlighting how he excluded and discriminated (Krane, 1997, 2001) her because of her competitive performance within the elite swimming context.

In contrast to the elite context, McMahon was also discriminated for her competitive performance in a masters swimming culture. However, discrimination occurred as a result of her extreme performance rather than her lack of performance. In this regard enacted stigma again occurred through labelling (Goffman, 1973; Link \& Phelan, 2001) her 'an ex Australian swimming representative' by a key member of the masters club who was awarding the prizes. Subsequently the two key members of the masters swimming club prevented her from winning a prize through the additional practice of penalising her time (i.e. $15 \mathrm{~s}$ were added to her winning time so she would come second rather than winning). Together, the acts of labelling, penalising her performance/swim time and taking away the prize had the effect of positioning the swimmer as a marginalised outsider (Goffman, 1973; Link \& Phelan, 2001). These revelations concerning enacted stigma and performance also highlight how the cultural expectations of 'competitive performance' differ in each sporting context, impacted by each culture's members or insiders (i.e. team manager; coach; club committee members). However, what remains similar is that those members (i.e. athletes) who do not meet the cultural performance standards/expectations/ideals of the specific sporting context/culture (i.e. poor or extreme performance) become stigmatised (i.e. enacted stigma).

\section{Felt stigma}

In regard to the second research question relating to whether the author experienced 'felt' stigma as a result of her competitive performance in two sporting contexts. The stories show that while the performance expectations in each sporting context differed, 'felt' stigma resulted for McMahon in both contexts. In this regard, the stories derived from experiences in both contexts highlighted feelings of 'shame', 'embarrassment' and a 'need to fit and be accepted' (Scambler, 2004) as a result of enacted 
stigma and as a result of her performance. In both contexts, McMahon blamed (Lekas et al., 2011) herself for her performance which is surprising given that she had performed well in the masters swimming context (i.e. 'maybe I should not have swam so fast'). It was also evident that she was overwhelmed with painful emotions as a result of her stigmatisation in both contexts and felt a need to protect herself from judgement and being further ostracised. In the elite swimming context, McMahon felt unworthy (Gray, 2002) of being part of the Australian swimming team as a result of her competitive performance and blamed herself for her poor result. In the masters swimming context, McMahon wanted to withdrawal from the context as a method of self-protection as a result realising she was positioned as an outsider. The two postscripts further outline the consequences of competitive performance stigma for McMahon. Rather than voicing our (the Authors) interpretations and analysis of these postscripts, we invite the reader/audience to draw their own conclusions (Ellis \& Bochner, 2000). Inviting the readers to draw their own conclusions from the postscripts was a conscious decision made by the Authors as we were well aware that our interpretations of these may indeed detract from the evocativeness of the story and/or lead the audience down one path over another, thus violating the assumptions of ethnodrama and creative forms of writing (Ellis \& Bochner, 2000; Smith, 2013; Sparkes, 2004). Whether the nature of the stigma experienced was felt or enacted, what was revealed was the considerable effects it had on the swimmer in terms of her emotional wellbeing and her subsequent social and participatory withdraw from the masters sporting context.

\section{Conclusion}

The purpose of this paper was to use one athlete's lived experiences to explore the notion of competitive performance stigma, a type of stigma yet to be contextualised in sport and exercise domains as well as highlighting the potential implications. Through analytic autoethnography, a post-stories analysis utilising Goffman's (1973) revealed that there was an importance placed on competitive performance and when this athlete failed to meet performance expectations, a number of consequences (enacted stigma) were imposed by others (i.e. insiders) within the culture/context.

The stories also revealed personal insights into how McMahon felt (felt stigma) in both contexts, such as anxiety, shame and embarrassment (Mansfield, 2010) and a desire to self-withdrawal (Schmalz \& Kerstetter, 2006) when the imposed performance standards were not met. In turn, these findings highlights how for those who do not meet cultural standards, what might occur as a consequence. Findings of this autoethnographic exploration suggest that the interactional processes of labelling, stereotyping, separation, status loss, and discrimination hold relevance to the social experiences of athletes and that these processes can have negative consequences (i.e. depression; self-doubt; social withdrawal) in their lives.

The present study also allowed us to highlight some of the taken for granted power structures and ideologies that are imposed by cultural insiders (e.g. coaches, managers, teammates) to an athlete. Previous research (McMahon, 2010; McMahon, Zehntner, et al., 2017) highlight how Australian swimming functions on meritocratic (i.e. winning at all costs) and technocentric (i.e. treating the athlete as an object of performance) principles. Given these points, we suggest from the present autoethnographic research that 'competitive performance stigma' may indeed contribute to these entrenched and taken for granted ideologies with certain psychological (e.g. depression; low self-worth) and behavioural (e.g. withdrawal from sport) effects for athletes who may not have the awareness or narrative resources to resist these. We suggest that further research is needed in regard to understanding how other swimmers have coped with 'competitive performance stigma' in these two sporting contexts. These findings may help us to better assist/equip other athletes who are stigmatised whether it be because of competitive performance or another characteristic that deviates from what is considered normal (Goffman, 1963). This future research is badly needed because being stigmatised indeed affects short term and long term participation in sport and physical activity (Schmalz \& Kerstetter, 2006) as well as health and wellbeing as was highlighted in this research. 


\section{Note}

1. Meritocracy has an extrinsic focus of achievement of competitive performance.

\section{Disclosure statement}

No potential conflict of interest was reported by the authors.

\section{References}

Allen-Collinson, J. (2005). Emotions, interactions and the injured sporting body. International Review for the Sociology of Sport, 40(2), 221-240.

Allen-Collinson, J., \& Hockey, J. (2008). Autoethnography as 'valid' methodology? A study of disrupted identity narratives. The International Journal of Interdisciplinary Social Sciences: Annual Review, 2(6), 209-218.

Anderson, E. (2002). Openly gay athletes: Contesting hegemonic masculinity in a homophobic environment. Gender \& Society, 16, 860-877.

Anderson, L. (2006). Analytic autoethnography. Journal of Contemporary Ethnography, 35(4), 373-395.

Barone, T. (2000). Aesthetics, politics, and educational inquiry. New York: Peter Lang.

Bochner, A., \& Ellis, C. (2016). Evocative autoethnography: Writing lives and telling stories. New York: Routledge.

Braun, V., \& Clarke, V. (2006). Using thematic analysis in psychology. Qualitative Research in Psychology, 3(2), 77-101.

Campbell, C., \& Deacon, H. (2006). Unravelling the contexts of stigma: From internalisation to resistance to change. Journal of Community and Applied Social Psychology, 16(6), 411-417.

Carless, D. (2012). Negotiating sexuality and masculinity in school sport: An autoethnography. Sport, Education and Society, 17(5), 607-625.

Crocker, J., Major, B., \& Steele, C. (1998). Social stigma. In D. T. Gilbert \& S. T. Fiske (Eds.), The handbook of social psychology (pp. 504-553). Boston, MA: McGraw-Hill.

Cunningham, G. B. (2008). Creating and sustaining gender diversity in sport organizations. Sex Roles, 58, 136-145.

Douglas, K. (2009). Storying my self: Negotiating a relational identity in professional sport. Qualitative Research in Sport and Exercise, 1(2), 176-190. doi:10.1080/19398440902909033

Edwards, L., Brown, D., \& Smith, L. (2016). We are getting there slowly: Lesbian teacher experiences in the post-section 28 environment. Sport, Education and Society, 21(3), 299-318.

Ellis, C. (2007). Telling secrets, revealing lives: Relational ethics in research with intimate others. Qualitative Inquiry, 13(1), 3-29.

Ellis, C., \& Bochner, A. (2000). Autoethnography, personal narrative, reflexivity: Researcher as subject. In N. K. Denzin \& Y. S. Lincoln (Eds.), Handbook of qualitative research (pp. 733-768). London: Sage.

Evans, J., \& Davies, B. (2004). The embodiment of consciousness; Bernstein, health and schooling. In J. Evans, B. Davies, \& J. Wright (Eds.), Body, knowledge and control: Studies in the sociology of physical education and health (pp. 207-218). London: Routledge.

Evans, J., Rich, E., \& Holroyd, R. (2004). Disordered eating and disordered schooling: What schools do to middle class girls. British Journal of Sociology of Education, 25(2), 123-142.

Goffman, E. (1963). Stigma. Englewood Cliffs, NJ: Prentice-Hall.

Goffman, E. (1973). Stigma: Notes on the management of spoiled identity. Harmondsworth: Pelican Books.

Goffman, E. (1981). Forms of talk. Philadelphia: University of Philadelphia Press.

Gray, D. (2002). Everybody just freezes. Everybody is just embarrassed: Felt and enacted stigma among parents of children with high functioning autism. Sociology of Health and IIIness, 24(6), 734-749.

Gulliver, A., Griffiths, K. M., \& Christensen, H. (2010). Perceived barriers and facilitators to mental health seeking in young people. BMC Psychiatry. doi:10.1186/1471-244X-10-113

Kauer, K. J., \& Krane, V. (2006). "Scary dykes" and "feminine queens": stereotypes and female collegiate athletics. Women in Sport \& Physical Activity Journal, 15, 42-55.

Kleinman, A., Wang, W.-Z., Li, S.-C., Cheng, X. M., Dai, X.-Y., Li, K.-T., \& Kleinman, J. (1995). The social course of epilepsy: Chronic illness as social experience in interior China. Social Science and Medicine, 40, 1319-1330.

Krane, V. (1997). Homonegativism experienced by lesbian collegiate athletes. Women in Sport \& Physical Activity Journal, 6 , 141-163.

Krane, V. (2001). We can be athletic and feminine, but do we want to? Challenging hegemonic femininity in sport. Quest (Grand Rapids, Mich.), 53, 115-133.

Lahman, M. K., Geist, M. R., Rodriguez, K. L., Graglia, P., \& DeRoche, K. K. (2011). Culturally responsive relational reflexive ethics in research: The three Rs. Quality \& Quantity, 45(6), 1397-1414.

Lekas, H., Siegel, K., \& Leider, J. (2011). Felt and enacted stigma among HIV/HCV co-infected adults: The impacts of stigma layering. Qualitative Health Research, 21(9), 1205-1219.

Link, B., \& Phelan, J. (2001). Conceptualising stigma. Annual Review of Sociology, 27, 363-385. 
Lopate, P. (2013). To show and to tell: The craft of literary non-fiction. New York: Free Press.

Mansfield, L. (2010). 'Fit, fat and feminine? The stigmatization of fat women in fitnessgyms'. In E. Kennedy \& P. Markula (Eds.), Women and exercise: Qualitative research on the body, health and consumerism (pp. 81-101). New York, NY: Routledge.

McMahon, J. (2010). Exposure and effect: An investigation into a culture of body pedagogies. Unpublished PhD thesis, University of Tasmania.

McMahon, J., \& Dinan-Thompson, M. (2011). Body work - regulation of a swimmer body: An authoethnography from an Australian elite swimmer. Sport, Education and Society, 16(1), 35-50.

McMahon, J., Penney, D., \& Dinan-Thompson, M. (2012). Body practices - exposure and effect of a sporting culture? Stories from three Australian swimmers. Sport, Education and Society, 17(2), 181-206.

McMahon, J., McGannon, K. R. \& Zehntner, C. (2017). Slim to win: An ethnodrama of three elite swimmers' 'presentation of self' in relation to a dominant cultural ideology. Sociology of Sport Journal. doi:10.1123/ssj.2015-0166

McMahon, J., Zehntner, C., \& McGannon, K. R. (2017). Fleshy, female and forty: A docudrama of a former elite swimmer who re-immersed herself into elite swimming culture. Qualitative Research in Sport, Exercise and Health. doi:10.1080/ 2159676X.2017.1340328

Owton, H., \& Sparkes, A. C. (2015). Sexual abuse and the grooming process in sport: Learning from Bella's story. Sport, Education and Society. doi:10.1080/13573322.2015.1063484

Parker, R., \& Aggleton, P. (2003). HIV and AIDS-related stigma and discrimination: A conceptual framework and implications for action. Social Science and Medicine, 57(1), 13-24.

Parry, D., \& Johnson, C. (2007). Contextualising leisure research to encompass complexity in lived leisure experience: The need for creative analytical practice. Leisure Sciences, 29(2), 119-130. doi:10.1080/01490400601160721

Satore, M., \& Cunningham, G. (2009). The lesbian stigma in the sport context: Implications for women of every sexual orientation. Quest (Grand Rapids, Mich.), 61, 289-305.

Scambler, G. (2004). Re-framing stigma: Felt and enacted stigma and challenges to the sociology of chronic and disabling conditions. Social Theory and Health, 2, 29-46.

Schmalz, D. L., \& Kerstetter, D. L. (2006). Girlie girls and manly men: Children's stigma consciousness of gender in sports and physical activities. Journal of Leisure Research, 38, 537-557.

Schneider, J. W. (1988). Disability as moral experience: Epilepsy and self in routine relationships. Journal of Social Issues, 44, 63-78.

Shilling, C. (1993). The body and social theory. London: Sage.

Smith, B. (2013). Sporting spinal cord injuries, social relations, and rehabilitation narratives: An ethnographic creative nonfiction of becoming disabled through sport. Sociology of Sport Journal, 30, 132-152. doi:10.1123/ssj.30.2.132

Smith, B. (2016). Authoethnography. Conference presentation. Qualitative research in sport, exercise and health conference. 1-3 September 2016, University of Chichester, UK.

Smith, B. (2017). Narrative inquiry and autoethnography. In M. Silk, D. Andrews, \& H. Thorpe (Eds.), Handbook of physical cultural studies (pp. 505-514). London: Routledge.

Sparkes, A. C. (2004). From performance to impairment: A patchwork of embodied memories. In J. Evans, B. Davies, \& J. Wright (Eds.), Body knowledge and control: Studies in the sociology of physical education and health (pp. 140-155). London: Routledge.

Sparkes, A. C. (in press). Autoethnography comes of age: Consequences, comforts and concerns. In D. Beach, C. Bagley, \& S. Marques da Silva (Eds.), Handbook of ethnography of education. London: Wiley.

Sparkes, A. C., \& Smith, B. (2014). Qualitative research methods in sport, exercise and health: From process to product. Abingdon, Oxon: Routledge.

Taub, D., Blinde, E., \& Greer, K. (1999). Stigma management through participation in sport and physical activity: Experiences of male college atheltes with a physical disability. Human Relations, 52(11), 1469-1484.

Wahab, S. (2003). Creating knowledge collaboratively with female sex workers: Insights from a qualitative, feminist, and participatory study. Qualitative Inquiry, 9, 625-642.

Wigginton, B., \& Setchell, J. (2016). Researching stigma as an outsider: Considerations for qualitative outsider research. Qualitative Research in Psychology, 13(3), 246-263.

Young, K., White, P., \& McTeer, M. (1994). 'Body talk': Male athletes reflect on sport, injury, and pain. Sociology of Sport Journal, 11(2), 175-194.

Zehntner, C., \& McMahon, J. (2014). The impact of a coaching/sporting culture on one coach's identity: How narrative became a useful tool in reconstructing coaching ideologies. Sports Coaching Review, 3(2), 145-161. 